\title{
David Oliver: Tube feeding and deteriorating patients-guidelines can take us only so far
}

\author{
David Oliver consultant in geriatrics and acute general medicine
}

Berkshire

Like most geriatricians, I look after many patients with progressive vascular or Lewy body dementia, severe disabling stroke, near end stage Parkinson's disease, and other progressive neurological conditions.

The natural history of patients with such conditions is that many run into problems with swallowing and lose their strength of cough. They're at risk of aspiration pneumonia. They find it hard to meet daily caloric requirements and risk poor nutrition. They may find it hard to take key medicines, which can further worsen swallowing, alertness, or overall medical fitness.

Family carers often do sterling work helping their loved ones to eat and drink on the wards, which even the most conscientious nurses find hard to match. In some families or cultures the idea of withdrawing intravenous fluids or artificial nutritional support, and focusing on palliative care, can require several sensitive and lengthy conversations, over days or weeks, for clinicians and family to arrive on the same page. It's sometimes necessary to carry on with interventions while that joint understanding is reached. We're often under pressure from families to use tube feeding and to continue intravenous fluids-or to let patients continue to take food and drink by mouth when it's become very risky.

There's no shortage of literature and official guidance on when tube feeding or its withdrawal is most clinically appropriate or effective ${ }^{1-4}$ or most legally ${ }^{56}$ or ethically ${ }^{7-9}$ permissible.

In the disease trajectories I've described, especially in the oldest patients and those with frailty and multimorbidity, patients are likely to become progressively disabled and have repeated infections and admissions, even if long term artificial nutrition and hydration are provided by percutaneous endoscopic gastrostomy (PEG) or radiologically guided gastrostomy (RIG). For instance, a systematic review of PEG feeding in patients with severe dementia found no improvement in survival and showed high complication rates. ${ }^{10}$ And these procedures carry a high risk of mortality in patients with severe disease and poor physical reserve. ${ }^{11-14}$

The more temporary use of nasogastric feeding is not without complications, including aspiration, fluid overload, discomfort, and tubes becoming dislodged and requiring repeated reinsertion, which may be distressing for patients. ${ }^{15}$ How many times do you try reinsertion before it becomes abusive? And shouldn't the patient's interests come before pressure from family members? I don't know many doctors in my field who would want to subject patients in the last year of life to potentially burdensome, distressing, or invasive treatment such as tube feeding.

However, my colleagues and I have also been in situations where, even if PEG or RIG isn't safe or desirable, nasogastric feeding is arguably neutral—causing no perceivable harm or distress and where the patient or relative has never expressed views about such treatment.

\section{As doctors we're well qualified to judge prognosis and effectiveness, but are we better qualified than patients' families to judge quality or purpose of life?}

I've also looked after several patients who, to the medical and nursing teams, appeared mostly to be in a state of diminished awareness or perpetually asleep—and yet who, when their families visited, woke up, interacted, and took small amounts of food or drink for taste and pleasure.

As doctors we're well qualified to judge prognosis and treatment effectiveness, but are we better qualified than patients' families to judge quality or purpose of life?

On several occasions my well intentioned attempts to withdraw tube feeding or not to recommence it, and to move towards a palliative approach, have been interpreted by families as an attempt to hasten the end instead of giving the patient every possible chance. This is a common scenario for doctors treating this patient group.

On other occasions, when I've personally inserted a nasogastric tube and it's stayed in for a week or three, the patient's family have been grateful after we managed to get the patient home towards the end of life, even when it's finally come out.

I know that there are huge pressures on hospital beds. I know that some readers will think it irresponsible to prolong or recommence nasogastric feeding just so that families can see 
that a patient has been given every chance to benefit from adequate nutrition and regular medicine before we move towards end-of-life care. But, after the patient has died, maybe that time will make it easier for them to cope with their loss. Is that so wrong?

Competing interests: See bmj.com/about-bmj/freelance-contributors/david-oliver. Provenance and peer review: Commissioned; not externally peer reviewed.

1 National Council for Palliative Care. Artificial nutrition and hydration: summary guidance. 2011. https://www.scie-socialcareonline.org.uk/artificial-nutrition-and-hydration-summaryguidance/r/a11G00000017uHUIAY.

2 Good P, Richard R, Syrmis W, Jenkins-Marsh S, Stephens J. Medically assisted hydration for adult palliative care patients. Cochrane Database Syst Rev 2014;4:CD006273. 10.1002/14651858.CD006273.pub3. 24760678

3 Good P, Richard R, Syrmis W, Jenkins-Marsh S, Stephens J. Medically assisted nutrition for adult palliative care patientswww.cochrane.org/CD006274/SYMPT_medically-assistednutrition-to-assist-palliative-care-patients. Cochrane Database Syst Rev 2014:4:CD006274.24760679

4 British Association for Parenteral and Enteral Nutrition. Standards and guidelines for nutritional support of patients in hospitals. 21 Dec 2012. www.bapen.org.uk/resourcesand-education/education-and-guidance/clinical-guidance/standards-and-guidelines-fornutritional-support-of-patients-in-hospitals.

5 BMA. Clinically assisted nutrition and hydration (CANH). 23 Jan 2018. https://www.bma. org.uk/advice/employment/ethics/mental-capacity/clinically-assisted-nutrition-and-hydration. 6 Horne M, Roper S. Can clinically assisted nutrition and hydration be withdrawn from PVS or MCS patients without prior authorisation by the court? 3 Oct 2017. http:// ukmedicaldecisionlawblog.co.uk/rss-feed/93-can-clinically-assisted-nutrition-and-hydrationbe-withdrawn-from-pvs-or-mcs-patients-without-prior-authorisation-by-the-court.

7 Royal College of Physicians. Oral feeding difficulties and dilemmas. 8 Oct 2010. https:// www.rcplondon.ac.uk/projects/outputs/oral-feeding-difficulties-and-dilemmas.

8 Druml C, Ballmer PE, Druml W, etal . ESPEN guideline on ethical aspects of artificial nutrition and hydration. Clin Nutr 2016;35:545-56. 10.1016/j.cInu.2016.02.006. 26923519

9 Harwood RH. Feeding decisions in advanced dementia. J R Coll Physicians Edinb 2014:44:232-7. https://www.rcpe.ac.uk/sites/default/files/harwood.pdf. 10.4997/JRCPE.2014.310 25318402

10 Brooke J, Ojo O. Enteral nutrition in dementia: a systematic review. Nutrients 2015;7:2456-68. https://www.ncbi.nlm.nih.gov/pmc/articles/PMC4425154/. $10.3390 /$ nu7042456 25854831

11 Mitchell SL, Tetroe JM. Survival after percutaneous endoscopic gastrostomy placement in older persons. J Gerontol A Biol Sci Med Sci 2000;55:M735-9. 10.1093/gerona/55.12.M735 11129395

12 Johnston SD, Tham TC, Mason M. Death after PEG: results of the national confidential enquiry into patient outcome and death. Gastrointest Endosc 2008;68:223-7. 10.1016/j.gie.2007.10.019 18329030

$13 \mathrm{Lim} \mathrm{JH}$, Choi SH, Lee C, etal . Thirty-day mortality after percutaneous gastrostomy by endoscopic versus radiologic placement: a systematic review and meta-analysis. Intest Res 2016;14:333-42. https://www.ncbi.nlm.nih.gov/pmc/articles/PMC5083262/. 10.5217/ir.2016.14.4.333 27799884

14 Desport J-C, Mabrouk T, Bouillet P, Perna A, Preux P-M, Couratier P. Complications and survival following radiologically and endoscopically-guided gastrostomy in patients with amyotrophic lateral sclerosis. 2005. https://www.tandfonline.com/doi/abs/10.1080/ $14660820410021258 \mathrm{a}$.

15 Ying I. Artificial nutrition and hydration in advanced dementia. Can Fam Physician 2015;61:245-8, e125-8. https://www.ncbi.nlm.nih.gov/pmc/articles/PMC4369630/.25767168 Published by the BMJ Publishing Group Limited. For permission to use (where not already granted under a licence) please go to http://group.bmj.com/group/rights-licensing/ permissions 